\title{
Does local government have capacity for enabling local economic development? Lessons from Jamaica
}

\author{
Commonwealth Journal of Local Governance \\ Issue 14: June 2014 \\ http://epress.lib.uts.edu.au/ojs/index.php/cjlg
}

\section{Eris D Schoburgh}

University of the West Indies

Mona Campus



\begin{abstract}
Implementation of the Caribbean Local Economic Development Project (CARILED) began in 2012 in seven countries for a duration of six years, to support sustainable economic growth in the region. CARILED has introduced the idea of local economic development (LED) to the 'development' debate in the region but has also brought the organisational capacity of local government, and local government's role as 'facilitator' of LED, to the fore. This paper assesses organizational behaviour and capability in local government in Jamaica to determine the state of readiness for a developmental role. The paper draws on two sets of research data to aid its analysis-a capacity audit (CAPAUD) conducted in 2010 and an organisational analysis (OA)commissioned by the Ministry of Local Government in 2010, both of which targeted a sample of local authorities in Jamaica.
\end{abstract}

The study found that when assessed against established criteria for an LED organisation, ie: research and information provision; marketing and coordination; learning and innovation; and leadership local government's institutional and organisational capacity for development is unevenly distributed. For instance, local leaders understood organisational purpose but efforts to give effect to this appeared undeveloped, sporadic and uni-directional. It was also evident that participatory strategies are used to gain information from communities but these were often devoid of systematic research methodologies rendering formal community impact on local planning negligent. Finally there is strong potential for the kind of administrative leadership required by a developmental local government to evolve,indicated by the quality of training, quantum of managerial/supervisory staff, and stability of staff establishment. However, this potential is threatened by the deficiencies in the non-traditional functional areas that are strategic to the organisation's effectiveness as a 'facilitator' of $L E D$, ie:alignment of community engagement/interface with LED priorities, diffusion of information technology in organisational processes, and utilisation of policy analysis and development. These findings contribute important policy relevant information to the discourses in the region about the construction of alternative solutions to institutional and organisational problems in response to the economic crises of small island developing states (SIDS).

\footnotetext{
${ }^{1}$ CARILED is funded by Canada's Department of Foreign Affairs, Trade and Development (DFATD) with support from the Federation of Canadian Municipalities (FCM) as well as Caribbean and Commonwealth countries. CARILED partners with 50 local governments to support the growth and development of 500 micro, small and medium enterprises (MSMEs). The project is valued at $\$ 23$ million CAD.
} 


\section{Introduction}

The Caribbean is a collection of small island states that differ in geographic and population size, socio-cultural composition, political status (not all are independent nations), and level and pace economic development. It is also a composite of regional economic and geopolitical sub-groupings, including:

- the Commonwealth Caribbean that comprises the former colonies of Britainthat have retained Westminster politico-administrative values and traditions to large degrees;

- Caribbean Community (CARICOM) ${ }^{2}$ which is a loosely designed trading bloc enabled by the Treaty of Chaguaramas of 1973 and which has been moving incrementally towards an economic union;

- the Caribbean Single Market and Economy (CSME), ${ }^{3}$, and

- the Organisation of Eastern Caribbean States (OECS) $)^{45}$

Irrespective of the sub-groupings, the Caribbean is defined by two main features: small size and vulnerability to external shocks (eg: global economic crises or natural disasters). These features informed the Composite Vulnerability Index (CVI) developed by a Commonwealth Secretariat and World Bank task-force,with the aim of leveraging special consideration for small-island developing states (SIDs) in international negotiations. The CVI has unfortunately not been adopted by the international development community but policy officials in the Caribbeanstill use vulnerability as a bargaining chip.

${ }^{2}$ CARICOM comprises 15 countries: Antigua and Barbuda, the Commonwealth of the Bahamas, Barbados, Belize, the Commonwealth of Dominica, Grenada, Guyana, Haiti, Jamaica, Montserrat, Saint Kitts and Nevis, Saint Lucia, Saint Vincent and the Grenadines, Suriname, and Trinidad and Tobago. Associate CARICOM Members are Anguilla, Bermuda, British Virgin Islands, Cayman Islands and Turks and Caicos Islands.

${ }^{3}$ Under the legal framework of the Revised Treaty of Chaguaramas, the CSME project is now scheduled for completion by 2015. As noted in the text, the original completion date had been scheduled for 1993. As Girvan noted: "The process of CSME implementation has been marked by missed targets and unevenness of compliance among member countries."'(Girvan 2008).

Girvan went on to state that $55 \%$ of the "agreed-to measures" that are required for the full implementation of the CSME, had not yet been implemented in 2007. The implementation deficit was principally in the second phase of the CSME project: that is, the completion of the single economy. Agreements on the single market (CSM) were substantially advanced. Thus, while most of the institutional infrastructure, tariffs, quotas and other impediments to free circulation of goods in CARICOM markets were removed, those unifying the sub-region as a single economic space were lagging. These included the failure to complete a single economy for services, investment, unified sectoral and social policies, government procurement, ICT, monetary and fiscal coordination.

${ }^{4}$ Seven micro-States in the Eastern Caribbean (with a combined population of 810,000 persons and a geographic area of just over 29,000 square kilometres) formed a sub-grouping in 1981, the Organisation of Eastern Caribbean States (OECS): Antigua and Barbuda, the Commonwealth of Dominica, Grenada, Saint Kitts and Nevis, Saint Lucia, Saint Vincent and the Grenadines, and

Montserrat. Within CARICOM, under the inaugurating Treaty, OECS member States are classified as Least Developed Country (LDCs) and, as such, are afforded asymmetrical commitments, obligations and benefits. However, this sub-grouping has since managed closer unity than the larger body. It operates with a common currency, pooled external reserves, a common Central Bank (ECCB), its own Secretariat, Joint Foreign Missions, and an Eastern Caribbean Supreme Court. OECS has achieved

much better economic performance and quality of life indicators than several of its "more developed" counterparts in CARICOM.

${ }^{5}$ Haiti and Cuba are sometimes treated as special cases but are important in the development profile of the Caribbean. 
This paper focuses on local government in the Commonwealth Caribbean,although local government does not exist or function effectively in all member countries, challenging the proposition of a developmental local government (DLG). A DLG is by definition 'development-oriented'-ie: a system of sub-national government mandated to design and implement policies aimed at increasing local economic growth resulting in positive social transformation of the lives of residents in a sustainable way. DLG is focused on improving the local environment to attract private sector investment and create employment, and its policy style is thus proactive and driven by demand for effective responses to local needs. A DLG thus requires a democratically decentralised institutional framework to bb operational.

The concept of a DLG and its close association with local economic development (LED) thus adds a new dimension to the rhetoric of local government reform and development strategies in the region, as the concept departs in a radical way from the 'politically-oriented' and 'controlled' local government systems that currently exist (for a description of these see e.g. Commonwealth Local Government Forum's Handbook; Schoburgh 2006; Ragoonath and Duncan 2009). Although for ECLAC's Report (2009) it seems that 'all that could be said on the topic[of Caribbean development] has already been said', this position has been rubbished in later analyses that assert a worsening development crisis in the region but also see new opportunities foraddressing development problems. Against the background of a decline in the region's traditional economic base that has increased the vulnerability of the states, LED presents new opportunities and is increasingly seen as a local government priority.

The World Bank defines LED as'a process by which public, business and nongovernmental sector partners, work collectively to create better conditions for economic growth and employment generation'.For the Commonwealth Local Government Forum (CLGF) LED is 'a process which brings together different partners in a local area to work together and harness local resources for sustainable economic growth'.Implementation of the 6-year Caribbean Local Economic Development Project (CARILED),aimed at sustainable economic growth in the region has examined the capacity of local government to assume the new role of 'facilitator' of LED. CARILED has placed DLG in the region firmly on the policy agenda.

This paper thus assesses organisational behaviour and capability in local government in Jamaica to determine the state of readiness for a developmental role. The paper draws on two sets of research data to aid its analysis. These are a capacity audit (CAPAUD) conducted in 2010 and an organisational analysis (OA)commissioned by the Ministry of Local Government in 2010, both exercises of which targeted a sample of local authorities in Jamaica. The paper provides important policy-relevant information for reformers and henceforth develops its arguments in four sections. Section one highlights the decentering development debate while section two engages the conceptual and practical issues involved in capacitating local government for LED, integrating a discussion on what CARILED portends for both local government reform and development policy in the region. The remaining two sections analyse the findings of the CAPAUD and discuss the implications for local government. 


\section{Development context and the search for a new paradigm}

'Development' defies precise definition, but it is clear from the discourse that it entails a process of graduated positive change in the economic, social and political dimensions of a country. The holistic approach to development has been acknowledged as a more sustainable basis on which to seek improved collective welfare and is emphasised in both the Millennium Development Goals (MDGs) and the Human Development Indices (HDIs). Despite the importance of the MDGs and HDIs, economic measures of development retain prominence, in social goals, particularly for Caribbean countries. ECLAC's Report (2009) observes that:

For many Latin American and Caribbean countries, the debt problem, brewed in the seventies, became a permanent obstacle to development in the eighties. It now threatens to remain an important development issue as well as a contentious topic in the arena of international economic co-operation. (p. 1)

The necessity of attaining eeconomic measures of development is validated further in two World Bank studies,A Time toChoose: Caribbean Development in the 21st Century(WB 2005a) and Towards a NewAgenda for Growth(WB 2005b) both of which highlighted the region's unrealised economic potential. The regional neoliberal debate on development, while accepting the need for a 'repositioning of the Caribbean withinglobalisation' has not fully embraced the World Bank's interpretation of Caribbean development problems and prescriptions, citing a disregard of indigenous analyses. Yet, as the ECLAC Report (2009) affirms:development strategies in the Commonwealth Caribbean have missed their targets, and its economicassessment of CARICOMhighlights the negative effects of the global economic crisis (p. 6) and places growth at the top of the list of economic performance indicators. ECLAC notes that for the period 2003-2007, GDP growth rates averaged just 3.2\%. More recently, the International Monetary Fund (IMF) found that growth in Latin America and the Caribbean in 2012 was 3\%, but in 2013 growth slowed to 2.6\%. Slight increases are predicted for 2014 and 2015 at $3.0 \%$ and $3.3 \%$ respectively ${ }^{6}$.

Arguably the starting point for a discourse around a DLG as a new paradigm of development in the region is Dirlik's1999 article, Place-based imagination: Globalism and the Politics of Place, in which therelationship between the global and the local is framed in a social and political dialectic in which place is recognised as both integral to human existence and as a counter ideology to globalisation. The claim is that 'place-based consciousness is closely linked to, and appears as the radical other of that conspicuous phenomenon of the last decade, globalism' (p. 151). The inference is, while globalisation changes the relationship between countries and groups, people make sense of these changes in more intimate settings in which they naturally coalesce. These settings are characteristically defined by relationships around the household, ie: localities or communities. Thus the 'advocacy of place' is a concern with the most appropriate means of sustaining the array of social and political relationships that define space. 'Place-based consciousness' in Dirlik's (1999) view 'reaffirms the necessity of reconstructing life from below in its very connectedness with nature' (p. 182).

${ }^{6}$ imf.org 
The World Bank's 2009 World Development Report:ReshapingEconomic Geographyalso makes a case for decentreing development because productive relationships are argued to be most evident in spaces in a sub-section of a country or region. The World Development Report (WDR) (2009) notes that, 'production concentrates in big cities, leading provinces, and wealthy nations' (p.xiii). However at the same time the WDR is pointing to the unevenness of development when it states that:

Half the world'sproduction fits onto 1.5\% of its land. Cairo produces more than half of Egypt's GDP, using just 0.5\% of its area. Brazil's three south-central states comprise $15 \%$ ofits land, but more than half its production. And North America, the European Union, andJapan-with fewer than a billion people - account for three-quarters of the world's wealth (xiii).

Placed-based interventions are a useful means of redressing the problems of global development and alleviating the problems of the 'bottom billion' for whom poverty and high mortality persist. It is acknowledged however that place-based interventions might not produce equal economic outcomes. In this vein the WDR cautions that 'economic growth will be unbalanced' with placed-based interventions and that 'to try to spread it out is to discourage it-to fight prosperity, not poverty'.

Barca's (2009) report about the economic state of the European Unionadvanced a similar position, assertingthat aplace-based policy is useful for tackling under-utilisation of potential and reducingsocial exclusion in specific places (vii). Barca (2009) asserts that in place-based policy, public interventions rely on local knowledge and are verifiable andsubmitted to scrutiny, while linkages among places are taken into account' (Ibid). For these reasons placed-based policy is seen as superior to alternative strategies that do not make theirterritorial focusexplicit. Moreover at times traditional development strategies hide their territorial focus behind a screen of space-blindness, failing tointegrate services, either assuming that the state knows best or relying on the choices of a few private actors (Barca 2009: vii).

Despite these compelling arguments, placed-based thinking has not necessarily engendered a new paradigm in local and regional development but rather reinforced the assumptions of earlier theories and models of LED (e.g. Plummer and Taylor 2001; Porter 1998; Myrdal 1957; Perroux 1950). Renewed interest in the value of local government in place-based thinking is emerging. For instance Tomaney (2010) argues that 'place-based approaches require strengthened local and regional institutions thatare able to assess and develop local economic assets in ways that amount to morethan "tailoring national policies"” (p. 7). Schoburgh (2012) makes a connection between local government,community development and LED, and with Bureauregard (1993) reasons that local institutions are at the nexus of these three processes (p. 26). The democratic value of local government is now bolstered by its economic value in place-based approaches with LED strategiesat the centre. 


\section{From project to policy: capacitating developmental local government}

Adequate capacity is a key determinant of the success of place-based and LED strategies. Capacity denotes the ability to do something, which manifests in individualcompetencies, collective capabilities and overall system ability. Nonetheless, neither acknowledgment of the significance of institutions and institutional capacity,noruse of both concepts in development discourses has clarified precisely the meaning of capacity (see e.g. Kaplan 2000; Christensen and Gazley 2008). In Kaplan's (2000) view the visible elements of human and material resources, organisational structure and procedures, do not tell the whole story about organisational performance. As Kaplan (2000) explains:

Organisations may have written statements of vision, of strategy, and of value, but these writtenstatements do not in any sense indicate whether an organisation actually has a workingunderstanding of its world.They do not indicate the extent to which an organisation feelsresponsible for its circumstances or capable of having an effect on them, or to which anorganisation is really striving to become a learning organisation,or to what extent it isdeveloping its staff or manifesting a team spirit or endeavour. Furthermore, they do notindicate the extent to which an organisation is reflective, non-defensive, and self-critical ( $\mathrm{p}$. 520).

The suggestion is that there is an invisible side to the organisation that ought to be taken into account when considering its capacity. Thus if capacity is being assessed from an institutional perspective, a distinction ought to be made between two dimensions of the organisation observed by Kaplan (2000) in the quote above, embodied in the 'rules in form' and the invisible elements of 'rules in use' (see e.g. Ostrom 2007). Both institutional and organisational analyses recognise the potency of the invisible elements on organisational performance and capacity.

The capacity of local governments or local agencies (where no local government exists) to facilitate the growth of micro, small and medium size enterprises (MSMEs) to stimulate local economic development in several Caribbean countries is the aim of CARILED, a six-year project valued at CDN\$23.2M. The CARILED project makes the most direct connection between local government and local economic development sincethe 1970s when,under the rubric of democratic socialism,local governments in Jamaica and Guyana were encouraged to facilitate community-based enterprises via partnerships with community councils. However, unlike the 1970s where the advocacy for a role for local government in development (see e.g Mill 1974) and strategies adopted had a strong political undertone, the current discourse favours economic growth in localities as means of improving the conditions of a significant portion of the population. CARILED is being implemented in CARICOM despite 'serious diseconomies of scale, low productivity, and high operating costs, for businesses and in the provision of basic public andinfrastructural services' (ECLAC 2009:12-13) and significant variations in resources and capacities in the region. The IMF's sobering observation isthat: 'most Caribbean economies continue to navigate ina sea of elevated debt, weak external demand, and unfavourable terms of trade' (IMF 2012 p. 5). 
CARILED offers new perspectives on, and approaches to, managing the development process. It incorporates cross-cutting themes such as gender in its focus on female-led MSMEs, and partnerships between local government/local organisations and local businesses. The expectation is that CARILED countries will see outcomes in local business expansion, improved local economic governance and service delivery, and sound policy. Lessons from CARILED will inform domestic policieson LED and assist in the design of innovativepolicy and management models relevant to the wider Commonwealth Caribbean.

Clearly CARILED is more than a project. It represents a new ideology about economic development models and strategy. It has introduced alternative ways of thinking about and practicing development in the region. However, although CARILED invokes a specific developmental role for local government it introduces a dialectic about the appropriateness of assigning this role to local government. First there is an uneasy nexus between Caribbean local governments and their organisational capacity for development. Second reform policies have assigned a role for local government beyond conventional local development eg: local business development, which situates local development in broader processes of community development. The question of what should be the focus in local government in the region -local development or LED - needs resolution in light of the implications for institutional and organisational capacity (Schoburgh 2012).

\section{Assessing local government capacity}

A capacity audit (CAPAUD) of eight local authorities in Jamaica was undertaken in 2010 to assess the institutional and organisational infrastructure of local government.The CAPAUD took the form a questionnaire that covered aspects of local authorities' organisational operations and relationships administered by the researcher. Respondents from each local authority were interviewed for this part of the audit - the mayor, the secretary manager, and the human resource director referred to in the study as 'local leaders' (inclusive of administrative and political leadership roles). Those items that relate specifically to the economic developmental role of the local authority as set out in Blakely and Bradshaw (2002) and expanded in Schoburgh (2012) ie: research and information provision; marketing and coordination; leadership; and learning and innovationwere isolated for analysis for this paper using descriptive statistics. The CAPAUD results are supplemented by findings of a Department of Local Government's commissioned organisational analysis of the fourteen local authorities in Jamaica. The assessment criteria used in this paper assume that the features of an economic developmental organisation, whether taken singly or in combination, are important indicators of organisational behaviour. In order to reduce the level of bias in the results the approach adopted in the analysis was to gauge, in the current context of reform, whether there are tendencies toward a transformational trajectory in the operations of the local authority. The next sections discuss the findings within these parameters. 


\section{Findings}

\section{Research and information provision}

The CAPAUD sought to determine the extent to which local authorities studied were orientated towards:

i) Generation of policy relevant information, and

ii) Identification of policy issues in line with clearly articulatedlocal developmental goals.

The measures used to assess these two features were a) local leaders' understanding of the mandate of the local authority, b) whether the mandate reflected the needs of the parish (administrative jurisdiction) and c) the method used by the local authority to ascertain local/parish needs.

In relation to the first measure - local leaders' understanding of the mandate of the local authority the majority of local leaders viewed provision of services to communities as the primary mandate of the local authority $(\mathrm{SO}=29.4 \%)$ (Figure 1).However two other interpretations were that its mandate is as the local governing body $(\mathrm{GL}=25.2 \%)$,or that the mandate is formalised in a legislative framework $(\mathrm{FI}=16.8 \%)$.

On the question of whether the mandate of the local authority reflects the needs of the parish, all respondents thought it did (Figure 2). Figure 3indicates that the most prevalent means of determining local needs was through a consultative process.

Figure 1: Local leaders' interpretation of mandate

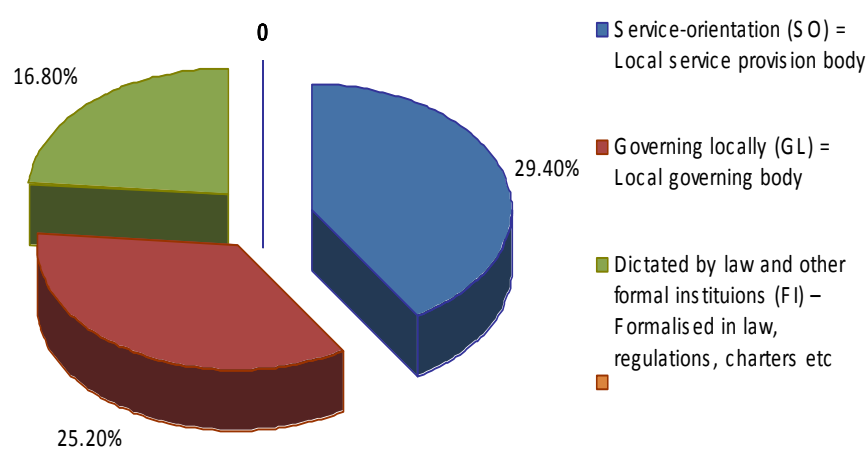

Figure 2: Does the mandate reflect the needs of the parish?



Figure 3:

Community needs-

assessment modalities 



The important finding is that local leaders understood organisational purpose but efforts to give effect to this were sporadic and uni-directional as actions were conceived from within the local authority and implemented internally and externally. Communities are consulted frequently but there is little evidence of the deployment of appropriate recording methodologies and storage of community data to inform policy.Incorporation of formal research findings into the operations of local authorities is negligible,and at the time of the capacity audit only one local authority in the sample had a development plan. The criterion of research and information provision is at a basic level and is not sufficiently oriented to transform the operations of the local authority even with evidence of an adoption of participatory methods in community and local authority interface.

\section{Marketing and coordination}

Successful LED activities have two key activities in common - promotion of development attributes (of the locale), and synchronisation of local interests for collective goals. Implicitly the local authority should have the capacity to develop strategies to assist in effective performance of these two tasks. The extent to which these features are evident in local authority operations in Jamaica were assessed by two indicators:

i) the nature of the internal business process of the local authority, and

ii) responsiveness to community demands in service delivery (demand capacity).

With respect to the internal business process of the local authority, questions were posed to respondents to find outwhether: the management of service delivery allows proper monitoring and evaluation of the quality of service provision; there were clearly established protocols/guidelines for service delivery, and staff had access to these protocols/guidelines, and the extent to which laws and bye-laws are translated into service targets and performance indicators. The aim was to assess the performance-orientation of the local authority. 
More respondents (50.0\%) said they had protocols/guidelines outside the law to monitor service delivery than those who said these protocols/guidelines did not (43.8\%) exist. Of the former group a significant majority $(70.0 \%)$ reported that these protocols/guidelines were available to all staff as against a few (20.0\%) who said they were not, and still fewer (10.0\%) who said they did not know if these were accessible to staff. The percentage margin between the local authorities in the sample that had these protocols/guidelines in place and those that did not is small $(6.2 \%)$, from which result one may infer that there are as many local authorities that use administrative guidelines as those that do not. ${ }^{7}$ The services in which these protocols/guidelines were used were in the category of regulation, the most cited activities being building approval and governance of burials on residential lots. Direct provision of services followed, with drain cleaning and road maintenance named most frequently. Interestingly the guidelines governing the building approval process are central government initiatives which means that although local leaders' cited these guidelines as an aspect of local innovation in service monitoring they are the outputs of decisions taken at a central government level.

Figure 4: Existence of monitoring mechanisms

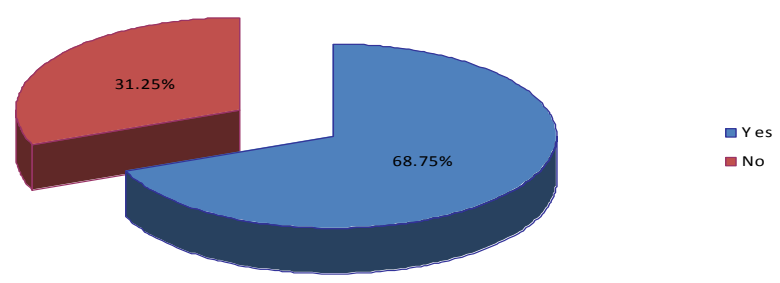

Figure 4shows that a majority of local authorities (68.8\%) claimed that they had mechanisms in place to monitor and evaluate service provision and these were identified as: status reports that were presented at committee meetings; 'expert' opinions of technical staff; internal audits; advice of the Portmore Municipal Council Advisory Committee (in the case of the Portmore Municipal Council); informal feedback from service users, and formal service surveys. Also mentioned were administrative actions such as setting timelines for staff, and the mayor's scope to include service monitoring and evaluation. However, $31.2 \%$ of the local authorities reviewed had no 'checklists or benchmarks' against which service quality is assessed.Nor was the development of a workplan with specific targets a general practice. For although a majority $(56.2 \%)$ said they used these methods, a contending minority (43.8\%) reported that they did not for different reasons as a few comments illustrate: "Service delivery is not systematically measured"; "We do not measure performance very well"; "We are trying to develop a system but nothing is in place yet". Moreover this 'majority' is reduced by a $12.6 \%$ margin when compared with the $68.8 \%$ that indicated that they had mechanisms in place to monitor and evaluate service provision(Figure 4). For local authorities that set service targets, these are usually annual as shown in Figure 5,timed to strengthen negotiations for budgetary allocation from central government, rather than to enhance performance at the local level.

\footnotetext{
${ }^{7}$ Especially if a presumption is made that the single response that selected 'don't know' means that there are no guidelines (for if there were it was be known).
} 
Figure 5: Frequency of setting service targets

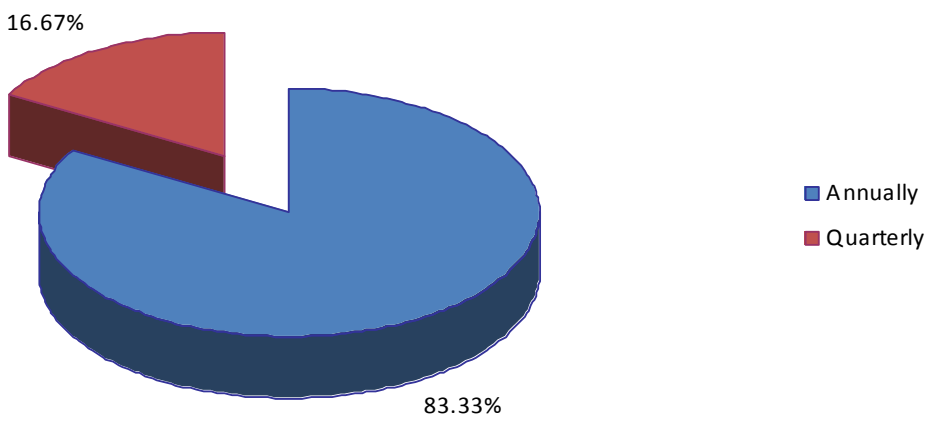

The level of demand capacity was assessed in the audit by examining how the local authority prepares to meet the expectations of citizens. Local leaders responded to questions about 'high demand' services to find out: whether communities were informed of the extent of its responsibility for the service, the level of demand for the service and whether the local authority has been able to meet the demand.The majority of respondents (91.7\%) thought that communities are aware of the local authority's responsibility the services, and even the few $(8.3 \%)$ who thought that communities were not aware indicated that it was important for them to become aware. An audit of key services shows the most commonwaysthat communities are informedabout, and express preferences for, local authority services.

Table 1: Community-local authority channel of communication

\begin{tabular}{|c|c|c|c|c|c|c|}
\hline Service & CM & RK & Cllr & Enf & PE/PR & $\mathrm{O}$ \\
\hline Road maintenance & $\sqrt{1}$ & $\sqrt{2}$ & $\sqrt{3}$ & & & \\
\hline Solid waste management & $\sqrt{1}$ & $\sqrt{3}$ & $\sqrt{2}$ & & $\sqrt{4}$ & $\sqrt{5}$ \\
\hline Approval of building plans & $\sqrt{4}$ & $\sqrt{2}$ & $\sqrt{6}$ & $\sqrt{1}$ & $\sqrt{3}$ & $\sqrt{5}$ \\
\hline Provision of potable water & $\sqrt{1}$ & $\sqrt{3}$ & $\sqrt{2}$ & & & \\
\hline Provision of street light & $\sqrt{0}$ & & $\sqrt{0}$ & & $\sqrt{0}$ & \\
\hline Licensing of places of amusement & & & & & $\sqrt{0}$ & $\sqrt{0}$ \\
\hline
\end{tabular}

$\mathrm{CM}=$ community meetings/consultations; $\mathrm{RK}=$ residual knowledge $; \mathrm{Cll} r=$ councilor; $\mathrm{Enf}=$ enforcement; $\mathrm{PE} / \mathrm{PR}=$ public education/relations; $\mathrm{O}=$ =- other

Table 1shows that consultations/community meetings (CM) emerge as the most frequently used means through which the local authority communicates with communities about its service responsibilities. The community also learns through historical/residual knowledge (RK). The third most frequently cited source of service information is the Councillor (Cllr). Interestingly, enforcement orders (Enf) that perhaps produce negative responses from citizens are the primary source through which information about regulatory services are provided to local citizens aremore important than public educational/relational (PE/PR) tools. 
Figure 6: Estimate of demand for local service by local authority

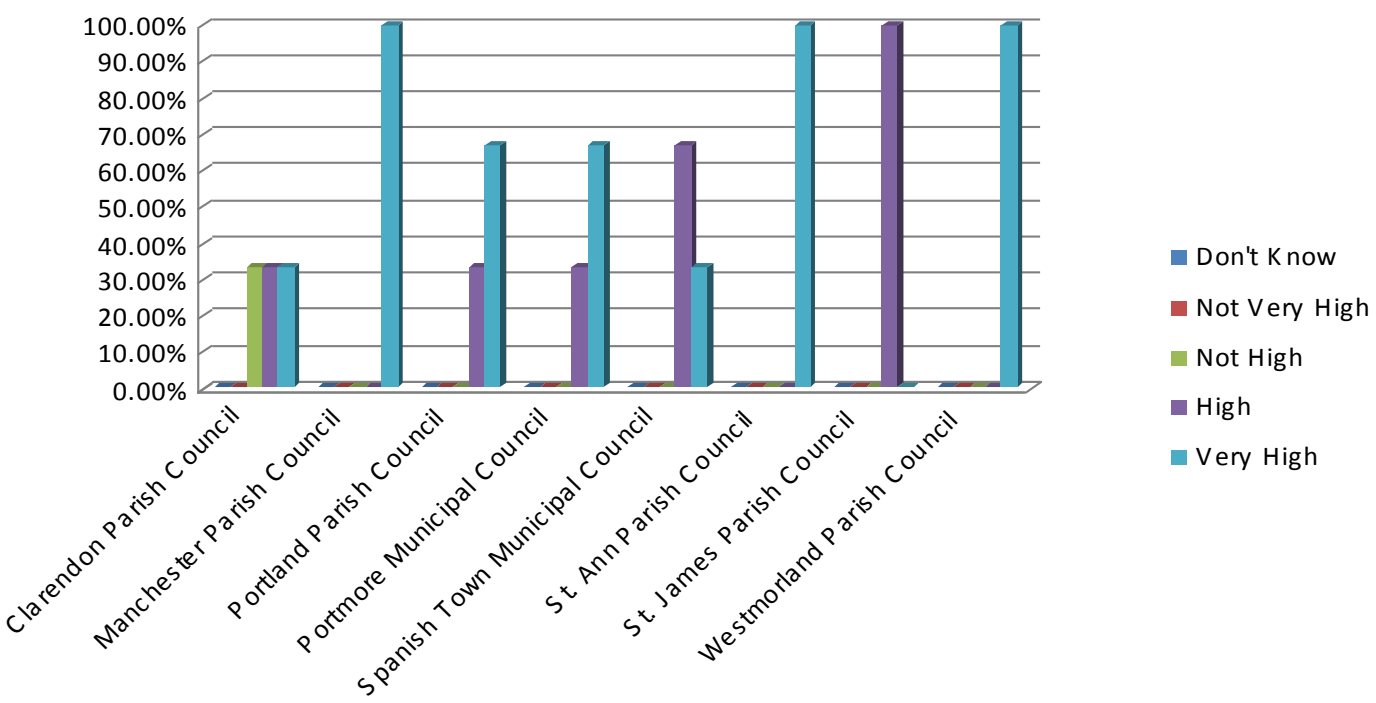

Figure 6 shows that the level of demand for all services in the sample of local authorities is estimated by local leaders to be between "very high"and "high" but in most cases no formal measure of demand was undertaken. In addition estimated demand for services is met 'sometimes' by all local authorities according to local leaders which brings into question their responsiveness to local needs.

Business process in the Jamaican local authority makes insufficient use of environmental inputs. This finding is reinforced by the absence of objective measurement of citizens' uptake of local services. The conclusion is that the local authority is operating without information about the true demand of current services or an understanding of the changes in uptake levels, service needs and expectations. The local authority would therefore need to build capacity for marketing and coordination functions as neither its business process nor its modes of communicating or extracting information from communities is at a level that can support a developmental role.

\section{Leadership}

High quality leadership is essential for the local authority to realise its fullest capacity. Yet, local authority leadership is a double-edged sword given the nature of the local authority as a political and administrative institution, and leadership can be tenuous given the blurred lines between the political and administrative dimensions of the organisation. The truth is that the influence of the political dimension transcends virtually all aspects of decision-making and is sometimes perceived by communities as a negative value in organisational performance given the proclivity for the local representatives to reflect party discipline in decision-making. Recognisably the extent to which developmental local government (DLG) is achieved depends in large measure on the outlook and quality of political leadership. 
The CAPAUD presumes that local elected representatives are qualified and legitimate leaders on the basis that they are chosen through a democratic process and therefore endowments such as education and training are incidental rather than germane to the transformative agenda implied. From the perspective of this study, it is perhaps more importantthat there is adequate administrative infrastructure to implement the new mandate that DLG will evolve. As a consequence the administrative dimension of the local authoritywas the focus of the audit. Particular attention is paid to the staffing establishment and the quality of the human resource at the higher tiers of administrative leadership as illustrated in Figure 7.

Figure 7: Staff establishment

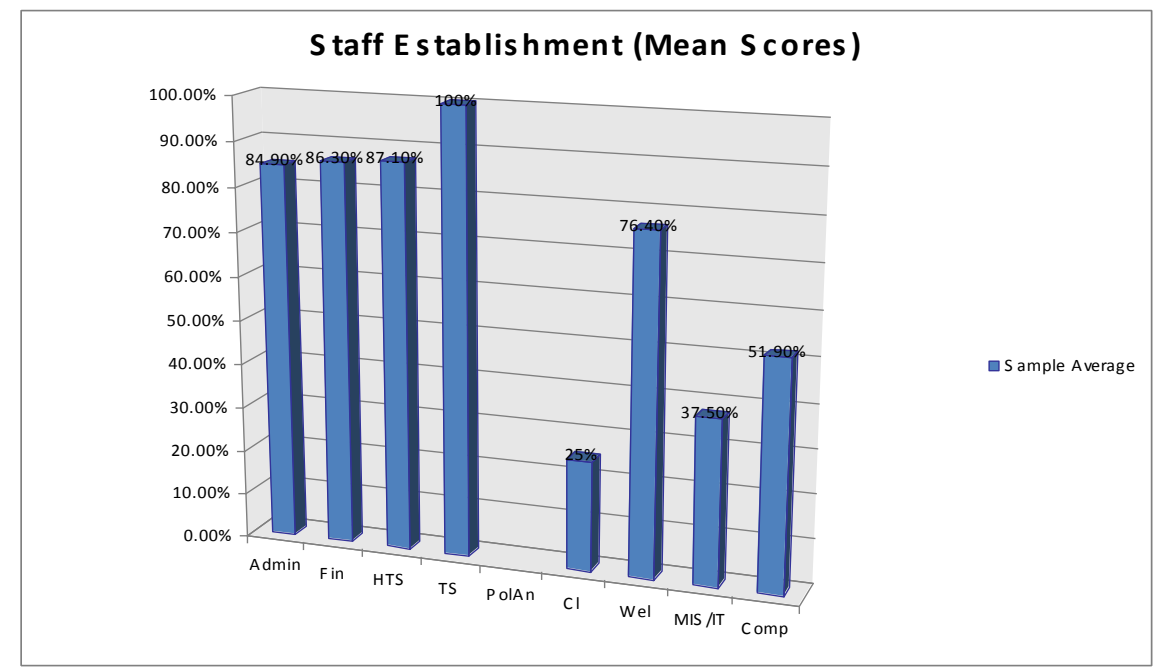

- All local authorities in the sample had their full quota of technical services staff, followed closely by administration in which two local authorities (St. Ann and Spanish Town ${ }^{8}$ ) had $90 \%$ and $89 \%$ of their staff, respectively.

- One local authority (Manchester) had its complement of managerial staff in the finance category with the remaining local authorities ranging between $80 \%$ and $90 \%$ of their establishment.

- One local authority (Clarendon) had its full complement of staff in the highly technical services category, the remaining local authorities indicating between $83 \%$ and $91 \%$ of establishment.

The local authority was assessed against the extent to which the staff establishment accounted for particular functions considered instrumental to a development orientation in local government ie: interaction with the community, utilisation of information technology (IT) in for example, management information systems (MIS), and policy analysis and development.

\footnotetext{
${ }^{8}$ Spanish Town is used to identify this local authority instead of St. Catherine, the name of the parish to distinguish it from the Portmore Municipal Council that is also located in St. Catherine.
} 
The results are that:

- With the exception of two local authorities, for most local authorities in the sample community interface positions were not part of the staff establishment, or in other cases were not filled;

- A similar situation exists with respect to IT/MIS that is in place in only three local authorities in the sample.

- No local authority accounts for a policy analysis and development position, independently.

The inference is that the managerial/supervisory staff establishment though not completely met is at a fair level in all the traditional functional areas of the local authority. However, non-traditional functions that are strategic to organisational effectiveness as a facilitator of development are at a low level in the organisations.

Figure 8: Level of adherence to educational qualifications by job category

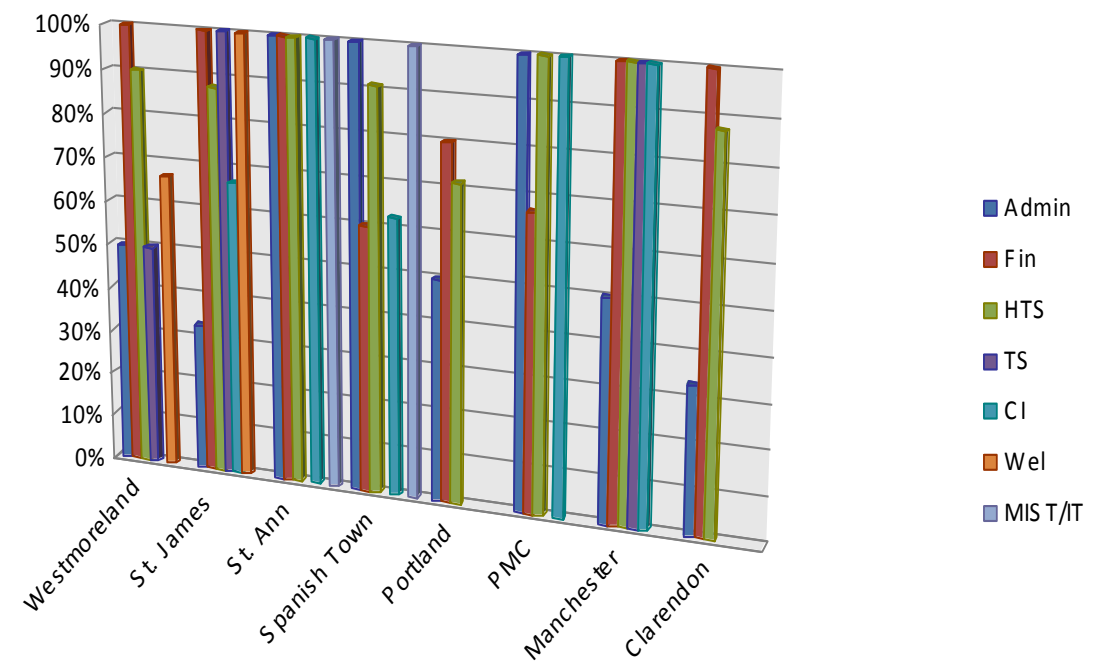

On the matter of the 'quality' of human resources that the local authority attracts, it was found as illustrated in Figure 8 that:

- Staff met entry requirements for the position most frequently in the administrative and technical services categories; followed by finance and IT/MIS, but less so in highly technical services and welfare/social services categories.

- All chief executive officers (CEOs) have attained university qualifications (though not necessarily a degree) with one exception at the time of the audit, where it was revealed that the CEO had equivalent qualifications, training and experience. 
Administrative leaders in Jamaican local authorities are equipped for their posts, if the measurement of capability is based on educational entry requirements and training. However leadership is functionally distinctive from management and it is unclear the extent to which educational qualifications and training are converted into leadership competencies. For instance the audit has not uncovered a significant difference between the management orientation of a CEO with a master of business administration (MBA) and that of other senior/middle managers with other social sciences degree or traditional management qualifications. It can be assumed that an MBA equips an individual with the requisite skills and competencies to develop and manage a business as well as innovate when the circumstances dictate. Local government reform is an appropriate context for utilising these skills. Innovation in local authorities in Jamaica is negligible evidenced by the absence of a clear organisational strategy in response to Ministry Papers 8 of 1993 and 7 of 2003. The audit found:

- A seeming lack of will on the part of senior managers to institute measures that might lead to higher organisational performance.

- At time of the CAPAUD, senior administrative leaders had not seized the opportunity to network and form alliances that could strengthen their leadership and management capacity in the context of reform and the obvious dynamism that the process brings to organisational operations.

- Arrangements akin to the Permanent Secretaries' Board that exists at the national level were absent leaving administrative leadership to operate in silos which mutes the organisation's ability to learn.

These issues bring into the question the capacity of the local authority for self-renewal and sustainability in light of limited expressions in organisational operations of foresight, innovativeness and autonomy even with strong endowments of education and training as manifested in its human resources.

\section{Learning and innovation}

Already the potential for organisational learning is implicated by aspects of the audit results discussed previously. Undoubtedly, information and communication technologies (ICTs) are important contributors to technical capacity as well as enablers of organisational learning and innovation. It is highly unlikely that DLG could be achieved without deliberate and sustained use of ICTs in local government operations. 
Under the parish infrastructure development programme (PIDP) implemented between 1993 and 1995 computerisation of local authorities resulted in the installation of 400 computers in all local authorities across the island with training of 405 staff members. Ministry Paper 7 of 2003 hinted of plans to activate a local area network (LAN) for local authorities However ICT diffusion appears to lack a clear strategy compounded by weak infrastructure that has retarded progress. The CAPAUD revealed that all local authorities in the sample demonstrated decent levels of computerisation in operations, but these were unevenly spread across the functional areas and which perhaps might be described as insufficiently developmentally oriented. For instance the audit showed that:

- There is an appreciable level of usage of computer technology in all functional areas of the local authority except policy development, community interface and MIS, but a majority of respondents rated the frequency of use as 'sometimes' (37.5\%; 62.5\% and $37.5 \%$ respectively).

- In welfare/social services the most frequent rating for use of computers was 'never' (50\%) with a minority indicating "sometimes" (37.5\%).

The nature of ICT use gives a better understanding of the extent of organisational readiness for innovation and by extension local government's development orientation. The CAPAUD found that:

- Local authorities' ICT use manifests in order of frequency as word processing, FMIS, and Web-based technology (e.g. emails).

Figure 9: Nature of ICT use in local authorities, Jamaica

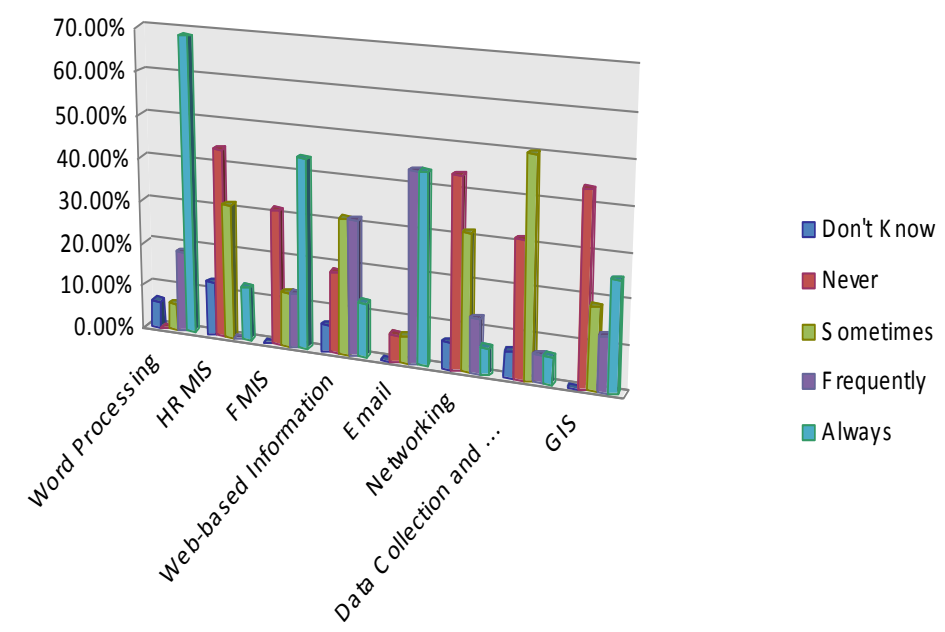

The conclusion is that ICTs in local authorities in Jamaica have not evolved beyond mundane usage and their potential as sources of innovation and enhancers of organisational capability is still to be realised. 


\section{Summary and analysis}

A clear indication from the results of the CAPAUD is that local government's capacity for development in Jamaica is unevenly distributed when assessed against the requirements of a local economic development organisation. Of course no organisation has all the requisite capacity to carry out its functions at all times. Moreover, LED is a multifaceted process drawing on all types of capacities that are not necessarily located within a single organisation. Nevertheless, irrespective of the nature of a local authority's strategy at any juncture - whether focused on service delivery or on enabling local economic development - deliberate steps need to be taken to bridge capacity gaps to assure the long term viability of the organisation. Contemporary approaches to public management are replete with concepts such as networked management,joined-up governance, andstrategic alliances that can increase capacity at different levels of the organisation.

Building capacity is a core function of leadership. It is an aspect of the visioning process that leaders are to oversee. Admittedly capacity-building is rarely accepted as a dimension of administrative responsibility in political institutions like local government. Administrative experience in Caribbean local governments suggests that local problem-solving in capacity building as in other dimensions of the local authority is more likely to be handled through extra-local institutions and processes rather than through the efforts of local leadership. This practice does not sit well with DLG that requires leadership with a particular mindset, orientation and style. Essentially DLG demands leaders that are aware of the environment in which the organisation operates, are appreciative of the particular context governing local policy decisions, understand the needs of the organisation, are attentive to factors that can contribute to organisational viability and resilience, and are willing to take risks to reduce uncertainty about future capacity requirements. The organisational analysis conducted by Price Waterhouse Coopers assessed the management ethos of the local authority as having "a high level of conservatism and resistance to change" (OPM/DLG/PwC 2010: 15).

Leadership does not operate in a vacuum and DLG is hampered by an organisational framework built on values that are no longer compatible with contemporary leadership and management technologies or development norms. There is little evidence also of an incentive structure that could assist in transforming this framework at the local level. The operations of local government in the Caribbean and in Jamaica specifically, lack a culture of high performance. 
LED must contend with a public management culture that is characterised by nested institutions and outdated embedded values such as:

a) Hierarchical organisational structures,

b) Paternalistic and autocratic policy and administrative leadership,

c) A self-regarding management ethos further demonstrated in unresponsiveness and a disregard of customer needs,

d) Management techniques that limit participation and which favour rank and statusover partnerships and teams, and

e) Technological phobia of the application of technology to policy and administrative processes (Brown 2010, Jacome 1992).

Furthermore, the persistence of nepotism as a basis for personnel appointments rather than merit or performance opens administration/management to corruption. 'Everyone knows everyone' encapsulates organisational cultural norms in the Caribbean (Brown 2010, Jacome 1992). In the context of local government this norm is a complicating factor inhibiting organisational change.The value system underpinning a culture of poor performance in local government collides with the normative framework of DLG that presumes a new way of doing things.

In contrast, a DLG has to rely on rational organisational framework to create and nurture the values essential for LED. The discourse on place-based approaches to development offers important clues about institutional and organisational value-creation strategies, and the experience with place-based approaches to LED inNorth Carolina (USA), for example, is instructive. Indeed the underlying philosophy in this instance is that sustainable LED is predicated on calculated and purposeful efforts accompanied by an appreciation for both the possibilities and limitations of a particular geographic space. The critical values accompanying this belief are that:

a) Local policy and management agendasare oriented around the triple bottom line - ie: ample return on economic, social, and environmental investments,

b) Local leadership and management talent and culture are economic assets,

c) Creative entrepreneurship and long-range vision define the local economic development process, and

d) Equity and sustainability are inherent to effective implementation of LED initiatives.

Finally, uneven capacity among Caribbean local governments as illustrated in the case of Jamaica does not bode well for private sector development which is a central pillar of both LED strategies and CARILED. The raison d'être of private businesses is profit-making, but the institutional values outlined previously (e.g. Brown 2010) are not necessarily conducive to creating an enabling environment for successful businesses. The findings of the CAPAUD suggest a level of incompatibility between the business development objectives of Jamaican local authorities and the goal of private sector development. The concept of 'facilitator' or 'enabler' must at some point make the shift to implementable practice in local government policy. 
Research and practice (see e.g. Hilhorstet al 2008) in local government's development of the private sector or general facilitation of LED suggest that key factors in LED include: the provision of high quality services linked to efficient and effective economic governance; ensuring that physical infrastructure needs are met to create an attractive environment for businesses, and efficient regulation especially in relation to effective governance of the 'commons' Schoburgh 2012). As Hilhorstet al(2008: 7) explain:

Local government can be an importantclient for the private sector, and they can use this influence to guide the type of economic growthand employment generation. They can privilege local enterprises, although they will have to staywithin the terms of law on procurement and free competition. They can also specify the work insuch a way that they become highly intensive in terms of labour requirements (for exampleinfrastructure-led economic development).

When these functional areas are examined they are clearly within the purview of local government. Therefore there can no longer be questions about the role of local government in LED activities. Caribbean local governments must assume a coordinating role in order to establish a relationship between it and the private sector. And any interpretation of the economic developmental role of local government is in essence an interpretation of the capacities and competencies that are needed.

\section{Conclusion}

Given the weak results of national economic development strategies in the Caribbean, LED emerges as a key alternative in the search for solutions to reduce national debt, strengthen the economy and create wealth. The sub-national level is especially significant in light of deleterious impact of the economic downturn on communities. LED is aligned to place-based approaches that are reorienting development thinking, giving rise to the significance of the 'local' or locality-based perspectives and action as a replacement for traditional approaches that emphasised strategies and interventions devised at the national level. A gradual decentering of development is emerging complemented by increased opportunity for the integration of goods and services fit to the context. High quality institutions are required for this approach to development and therefore a niche is being created for a new kind of local government, endowed with a range of capacities. Wherever an LED strategy is adopted it sets in motion a raft of institutional changes with primary focus on local government.

The findings from the CAPAUD of a sample of local authorities in Jamaica suggest that the present institutional environment for LED is not sufficiently supportive. A crucial point is that irrespective of the capacity building strategies and organisational structuring that are implemented in the future; the matter of high quality leadership must be a concern. Understandably the process of reorienting the local authority to an economic developmental focus cannot disregard other responsibilities of the organisation. Fundamentally perhaps the kind of revolutionary change that is sought in an LED policy context requires keener attention to the invisible elements of the local authority, giving a strong signal as to the priority for organisational change in giving effect to the concept of a DLG in Jamaica as well as the Caribbean. 


\section{References}

Amis, P. (2007) Financing Decentralisation and Local Government to Meet the MDGs Commonwealth Local Government Forum and ComHabitat submitted to Commonwealth Finance Ministers Meeting 2007.

Barca, F. (2009) An Agenda for a Reformed Cohesion Policy: A place-based approach to meeting European Union challenges and expectations. Europa.eu at: http://ec.europa.eu/regional_policy/archive/policy/future/barca_en.htm. (Accessed March 27, 2013).

Baser, H. and Morgan, P. (2008) Capacity, Change and Performance. Study Report. ECDPM.

Boamah, H. (1989). Public finance in small open economies: the Caribbean experience. Greenwood Publishing Group.

Christensen, R.K. and Gazley, B. (2008) Capacity for Public Administration: Analysis of Meaning and Measurement. Public Administration and Development. 28 pp. 265-279.

Brown, D. R. (2010) Institutional Development in Small States: Evidence from the Commonwealth Caribbean. Halduskultuur - Administrative Culture 11 (1), 44-65.

DFID (2009) UK Local Government Alliance for International Development. DFID White Paper Response.Dirlik, Arif. 1999. Place-based imagination: Globalism and the Politics of Place.Review 22 (2) pp.151-187.

ECLAC (2009) Caribbean Development Report Volume II. United Nations Publication.

Hilhorst, T., Baltissen, G. and Lodenstein, E. (2008) What can rural local governments contribute to private sector development? KIT Working Papers Series G2. Amsterdam: KIT.

Ibitoye, I. (2009) Small States in Global Economic Slowdown.Commonwealth Trade Hot Topics Issue 64 (October).

IMF (2012) Regional Economic Outlook - Update, Latin America and the Caribbean. [October] imf.org.

Jamaica. Ministry Paper 7 of 2003..

Jamaica. Ministry Paper 8 of 1993.

Kaplan, A. (2000) Capacity building: Shifting the Paradigms of Practice. Development in Practice, Volume 10, Numbers 3 \& 4 (August) pp. 517-526.

Myrdal, G. (1957). Economic Theory and Underdeveloped regions.London: Duckworth.

Ostrom, E. (2007) Institutional Rational Choice: An Assessment of the Institutional Analysis and Development Framework. In Sabatier, Paul, ed. 2007.Theories of the Policy Process. Boulder, CO: Westview Press.

Perroux, F. (1950) Economic Space: Theory and Applications. The Quarterly Journal of Economics.64,(1) (February), pp. 89-104.

Plummer, P. and Taylor, M. (2001) Theories of local economic growth (part 1): concepts, models, and measurement. Environment and Planning A. 33. pp. 219-236.

Porter, M. (1998) The Adam Smith Address: Location, Clusters, and the "New" Microeconomics of Competition. National Business Association for Business

Economics.http://www.econ.nyu.edu/dept/courses/niemira/980107.pdf. Accessed January 31, 2011.

Schoburgh.E. (2012)Local Government and Local Development: Bridging the Gap through Critical Discourse: Evidence from the Commonwealth Caribbean. Commonwealth Journal of Local Governance Issue 10: December 2011- June, 2012. Pp 5.31. http://epress.lib.uts.edu.au/ojs/index.php/cjlg.

Tomaney, J. (2010) Place-based Approaches to Regional Development: Global Trends and Australian Implications. A Report for the Australia Business Foundation.

World Bank (2005) A Time to Choose: Caribbean Development in the 21st Century.

World Bank (2005) Towards a New Agenda for Growth.

World Bank (2009) ReshapingEconomic Geography. 